\title{
Estudos sobre educação rural no Brasil: estado da arte e perspectivas $^{1}$
}

\author{
Maria Nobre Damasceno \\ Bernadete Beserra \\ Universidade Federal do Ceará
}

\section{Resumo}

0 presente estudo mapeia e discute o conhecimento produzido na área da Educação Rural, nas décadas de 1980 e 1990, com o objetivo de esboçar o "estado da arte" neste campo de investigação. Entre outros aspectos, apresenta e discute as temáticas de estudo mais recorrentes, a organização regional dessa produção e, ao final, as tendências atuais e as temáticas ainda não suficientemente exploradas. Caracterizadamente bibliográfico, e restrito à produção acadêmica na área de Educação, este estudo baseou-se nas seguintes fontes: 1. a produção discente de mestrado e doutorado do banco de resumos de dissertações e teses da Associação Nacional de Pós-graduação e Pesquisa em Educação - ANPEd; 2. os periódicos acadêmicos nacionais; e 3. os principais livros enfocando a temática da Educação Rural publicados no período. Uma das conclusões é que é cada vez maior o número de trabalhos que discutem o problema da educação rural da perspectiva da população a que se destina, ou seja, os trabalhadores rurais. Tal tendência, porém, não nasce da clarividência ou excessiva sensibilidade dos estudiosos do tema, mas das próprias circunstâncias da realidade sob estudo, já que são os próprios trabalhadores rurais que, por meio da sua organização política, tornam-se suficientemente visíveis para chamarem sobre si a atenção dos estudiosos.

\section{Palavras-chave:}

Estado da arte - Educação rural - Educação rural no Brasil Movimento social no campo.

Correspondência:

Maria Nobre Damasceno

Rua Joaquim Trajano, 136

60874-650 - Fortaleza - CE

e-mail: mnobre@secrel.com.br

1. Uma versão preliminar deste artigo foi apresentada no III Congresso / Argentino y Latino Americano de Antropologia Rural. Tilcara, Jujuy, Argentina, em março de 2004. 


\title{
Studies on rural education in Brazil: State-of-the-art and perspectives $^{1}$
}

\author{
Raquel Goulart Barreto \\ Universidade do Estado do Rio de Janeiro
}

\begin{abstract}
This work maps out and discusses the knowledge created in the area of Rural Education during the 1980s and 1990s, with the purpose of outlining the 'state-of-the-art' in this field of investigation. Among other aspects, this article introduces and discusses the most recurring themes of study, the regional organization of this production and, towards the end, the current trends and the themes still not sufficiently explored.

Markedly bibliographical, and restricted to the academic production in the area of Education, this work is based on the following sources: 1. Master and doctoral dissertations found in the ANPEd (National Association for Graduate Studies and Research in Education) database; 2. Brazilian academic journals; and 3. the main books focusing on the theme of rural education published within this period of time. One of the conclusions is that there is an increasing academic production discussing the issue of rural education from the point of view of the target population, that is, the rural workers. Such trend, however, is not born out of foresight or extreme sensitivity on the part of the researchers, but springs from the circumstances of the reality under study, since the rural workers, through their political organization, have become sufficiently visible to draw to themselves the attention of researchers.
\end{abstract}

\section{Keywords}

State-of-the-art - Rural education - Rural education in Brazil Rural social movement.

\section{Contact:}

Maria Nobre Damasceno

Rua Joaquim Trajano, 136

60874-650 - Fortaleza - CE

e-mail: mnobre@secrel.com.br

1. A preliminary version of this article has been presented to the III Congresso Argentino y Latino Americano de Antropologia Rural, Tilcara, Jujuy, Argentina, March 2004. 


\section{Introdução}

O objetivo do presente estudo é mapear e discutir o conhecimento produzido na área da Educação Rural, nas décadas de 1980 e 1990, com o propósito de esboçar o "estado da arte" neste campo da investigação. Entre outros aspectos, estamos interessadas em explicar as temáticas privilegiadas, a organização regional dessa produção e, ao final, apresentar e discutir as tendências atuais e as temáticas ainda não exploradas suficientemente.

Um dos primeiros problemas com que nos defrontamos quando se discutem e se avaliam os estudos na área de Educação Rural hoje é o do próprio estatuto do termo rural. Diferentemente do que se propalava quando a educação rural era um projeto ligado ao desenvolvimento do país cuja vocação de país agrícola demandava políticas específicas de educação rural, hoje a realidade é bastante distinta e o novo rural brasileiro guarda pouca semelhança com o da década de 1950, inclusive no sentido da revalorização ocorrida com a crise das cidades (Sorj, 1998; Graziano, 1999; Veiga, 2002). ${ }^{2}$

Diferentemente do que propunham os Estados Unidos e os outros países que tomaram a dianteira e o controle do desenvolvimento industrial, não faz mais sentido pensar em vocação agrícola ou qualquer outro tipo de vocação das nações fora das políticas imperialistas e colonialistas que as definem. Portanto, quando nos idos de 1950 falava-se de uma educação rural que promovesse a valorização do trabalho rural supunha-se que fosse possivel organizar artificialmente o já iniciado processo de urbanização do país. Supunha-se, contra as políticas e ideologias industriais e urbanas mais gerais, que fosse possivel convencer os trabalhadores rurais de que o seu papel era o de garantir o sentido da vocação agrícola do país. Uma vez educados no sentido de valorizar o trabalho agrícola (que contraditoriamente não era valorizado por mais ninguém), tais trabalhadores aceitariam a sua missão de salvaguardar a vocação agrícola do país. Mas, por que graça conseguiriam os pro- fessores, sozinhos, lutar contra todos os outros meios de comunicação que insistentemente afirmavam que o urbano era sinônimo de progresso, civilização e de todos os valores positivos que se difundiam à época?

É nesse contexto que vários programas de educação rural são implementados e, por razões óbvias, além das dificuldades da dispersão da população rural, sistematicamente fracassam - ou pelo menos fracassam em relação às metas propostas (Calazans, 1993). De tal modo que até hoje o problema da educação rural básica não foi resolvido, e não é por acaso que os mais altos índices de analfabetismo do país estão localizados na zona rural e, dentre elas, naquelas das regiões cuja posição na divisão nacional do trabalho não exige uma produção baseada no trabalho qualificado. ${ }^{3}$

A despeito de tímidas iniciativas no final do século XIX, é somente a partir da década de 1930 e, mais sistematicamente, das décadas de 1950 e 1960 do século XX que o problema da educação rural é encarado mais seriamente - o que significa que paradoxalmente a educação rural no Brasil torna-se objeto do interesse do Estado justamente num momento em que todas as atenções e esperanças se voltam para 0 urbano e a ênfase recai sobre o desenvolvimento industrial. Lembremo-nos, por exemplo, da meta do governo Juscelino Kubitschek de desenvolver cinqüenta anos em cinco. As ideologias do progresso que incluíam necessariamente a extensão do urbano destroem a vocação agricola de todas as gerações independentemente de se em países de vocação agrícola ou

2. De acordo com o IBGE, Censo de $2000,82 \%$ da população brasileira é urbana. Veiga (2002) argumenta, porém, que a metodologia de cálculo atualmente utilizada não é adequada porque inclui na categoria de urbano municípios que, de acordo com a OCDE - Organização de Cooperação e de Desenvolvimento Econômico, são rurais já que apresentam densidade demográfica inferior a $150 \mathrm{Hb} / \mathrm{km} 2$. Se os critérios de urbanização adotados pela OCDE fossem aplicados ao Brasil, apenas cerca de $60 \%$ da população seria considerada urbana.

3. Em $2000,29,8 \%$ da população rural era analfabeta contra $10,3 \%$ da população urbana. 0 índice do analfabetismo rural no Nordeste era o mais alto de todos: 42,7\% contra, por exemplo, o índice do Sul que era o mais baixo de todos e quase quatro vezes menor do que o do Nordeste: $12,5 \%$. Fonte IBGE - Censo Demográfico de 2000. 
não. 0 progresso e o desenvolvimento, principais expressões da narrativa evolucionista, exigiam o fim do campo e do camponês, - já que ambos eram sinônimos de passado e atraso. Em tal narrativa cabiam todas as matizes políticas, independentemente de capitalistas ou socialistas. Mas o que fazer com a vocação dos países então denominados subdesenvolvidos? Investir na agricultura e na produção e difusão do conhecimento técnico agrícola e, por meio desses investimentos, desenvolver uma mentalidade de respeito e valorização da atividade agrícola. Tanto a vocação quanto a forma de torná-la realidade são decididas já pelo novo centro hegemônico do ocidente no pós-guerra, os Estados Unidos. Não é à toa que os programas e projetos de educação rural sob o patrocínio de instituições norte-americanas tomam grande impulso a partir de então. É o caso, por exemplo, da Associação Brasileira de Assistência Técnica e Extensão Rural (ABCAR), que, criada em 21 de junho de 1956, e incumbida de coordenar programas de extensão e captar recursos técnicos e financeiros, era patrocinada por organizações ditas de cooperação técnica diretamente ligadas ao governo dos Estados Unidos (IIAA, ICA, AID, Aliança para o Progresso, etc.) ou ao grande capital monopolista americano (Fundações Ford, Rockefeller, Kellog, etc.). ${ }^{4}$

Apesar do esforço de implantação da sua hegemonia sobre o Brasil e toda a América Latina, inclusive claramente expresso em políticas como a Política da Boa Vizinhança, do governo Roosevelt, em 1932, não há, porém, no período que vai do fim da Segunda Guerra até o Golpe Militar de 1964 nenhuma tendência absolutamente hegemônica. De tal modo que muitos programas de Educação Rural serviam de instrumentos de difusão de ideologias inclusive opostas às pretendidas pelo governo americano. Semeadas numa sociedade em transição e marcada por extraordinária desigualdade social, tais projetos e políticas têm conseqüências as mais diversas, inclusive a de mobilizar as populações rurais já vítimas da modernização no campo, contra os efeitos negativos que esta vem produzindo sobre as suas vidas. É o caso do conjunto de movimentos sociais que, articulados aos partidos políticos de esquerda ou à lgreja católica, vão produzir um estilo de educação e um tipo de saber bastante diferente dos pretendidos pelas necessidades imperialistas do governo americano, entre os quais se destaca a pedagogia de Paulo Freire que vai, depois, influenciar uma das tendências acadêmicas do estudo do rural: a da educação e movimentos sociais no campo (Damasceno, 1992).

Após a ditadura militar, período durante 0 qual as políticas industriais e agrícolas mudaram completamente a face do país, são outros os problemas e questões que se apresentam tanto para o rural quanto para a educação rural. É também durante esse período e já em conseqüência da influência do sistema educacional americano sobre o brasileiro que os primeiros programas de pósgraduação em educação são fundados, e surge também uma pesquisa mais sistemática sobre a educação brasileira, inclusive motivada pelas associações nacionais de pós-graduação e pesquisa que proliferam a partir dos meados de 1970.

\section{Estudos rurais no Brasil: um mapa}

Embora tenhamos consciência de que outras disciplinas, especialmente a agronomia e a sociologia, também produzem conhecimento na área de Educação Rural, concentramos a nossa atenção na produção científica na área de Educação. Com o propósito de apresentar um quadro da produção acadêmica no período citado, pesquisamos: 1 . a produção discente de mestrado e doutorado do banco de resumos de dissertações e teses da ANPEd $;^{5}$ 2. os periódicos acadêmicos nacionais e, neste caso, como

4. Ver, entre outros, Vieira, 1954; Padilha, 1982; Calazans, 1979, 1993; Demo, 1980; Gusso, 1978; Maia, 1982; Pinto, 1981; Werebe, 1968.

5. Também pesquisamos a base de dados da Capes do período 19962001 e os resultados confirmam, em termos numéricos, os da base de dados da ANPEd, embora surjam novos temas em função dos interesses das diversas disciplinas no mundo rural. Ou seja, ao invés de pesquisarmos especificamente a educação rural, pesquisamos o rural e tudo que foi incluído sob este descritor. 
é marginal a temática, consultamos também periódicos "regionais" entre os quais o da nossa própria Faculdade de Educação, a Revista Educação em Debate; ${ }^{6}$ e 3. os principais livros enfocando a temática da educação rural publicados no período. ${ }^{7}$

A primeira observação se refere à quantidade de estudos produzidos na área e o seu lugar relativo em relação às outras áreas. Como podemos observar no Quadro1 a proporção média ao longo do período pesquisado é de doze trabalhos na área de Educação Rural para mil trabalhos nas demais áreas da Educação. Uma porcentagem dezessete vezes inferior à do número de habitantes no campo em relação ao da cidade, se tomarmos como referência os dados estatísticos do IBGE do ano 2000, de acordo com os quais a população rural representa $18,75 \%$ da população brasileira. ${ }^{8}$

É claro que nenhum lugar político ou social numa sociedade capitalista pode ser definido em função da porcentagem de certas classes ou grupos em relação à população total. Ao contrário, as políticas são definidas no mais das vezes em função do poder de barganha dos setores envolvidos. Nesse caso, a importância relativa do tema está relacionada antes de qualquer coisa ao valor relativo do setor agrícola em relação aos setores industrial e de serviços. Além disso, é importante chamar atenção para o fato de que a própria idéia da universalização da educação é decorrente da universalização da demanda do mercado de trabalho por um nível mínimo de educação/especialização. ${ }^{9}$ Não sendo um requisito para o trabalho rural e, nesse caso, indispensável para a reprodução do capital, a educação rural é negligenciada. Já do ponto de vista da prioridade a programas de educação rural, sempre valeu aquela idéia que um dia Darcy Ribeiro defendeu a respeito da educação de adultos (Ribeiro, 1978). Ou seja, considerando que os recursos estatais para as políticas públicas sempre foram bastante limitados, seria preferivel investir recursos em áreas que a médio ou longo prazos apresentariam resultados positivos.
Darcy dizia que era melhor investir na educação básica porque o analfabetismo adulto seria resolvido mais dia menos dia pela morte. Crença semelhante sempre rondou a educação rural já que se acreditava que a evolução natural da sociedade capitalista levaria à extinção do rural. Noutras palavras: acaba-se o rural e acabam-se juntos os problemas da educação rural. A despeito disto, porém, e em função de pressões internas e externas, várias campanhas de educação rural foram empreendidas, inclusive campanhas diferenciadas como a do Edurural, que funcionou entre 1981 e 1987, e cuja realização exclusivamente no Nordeste tinha o objetivo de diminuir a diferença entre os indices de analfabetismo rural nesta região e nas demais. ${ }^{10}$

Além do valor relativo do rural - ou do seu valor ideológico-cultural - a escassez de estudos na área é também fruto da dificuldade de financiamento de pesquisas e da relativa facilidade de desenvolvimento de pesquisas nas áreas urbanas onde o próprio pesquisador habita. Mas a nossa hipótese é de que, além desses motivos apresentados, o desinteresse generalizado pela temática reflete o desinteresse do Estado pelo problema pelos motivos acima apresentados. Aqui é importante abrir um

6. Para uma lista de todos os periódicos pesquisados ver Quadro 5. 7. Utilizamos os seguintes descritores para a busca no bando de dados da ANPEd: educação rural, meio rural, zona rural, assentamentos rurais, assentados rurais, movimento dos sem- terra, movimentos sociais, campo, trabalhadores rurais.

8. Se compararmos o número de estudos com o número de habitantes para cada ano investigado a proporção geral de estudos é ainda menor.

9. Este raciocínio explica porque a extensão rural foi organizada muito mais eficientemente do que a educação rural. 0 que significa que mais importante do que a educação universal para o homem do campo sempre foi o treinamento específico em técnicas e conhecimentos que permitissem a modernização da agricultura nos termos em que interessava aos centros internacionais de poder, especialmente, os Estados Unidos.

10. Concebido como uma estratégia para diminuir a defasagem econômica entre o Nordeste e as demais regiões do país, o "Programa de Educação Básica para o Nordeste Brasileiro (Edurural) foi lançado em 1980 e envolveu recursos da ordem de 92 milhões de dólares, dos quais $32 \mathrm{mi}-$ Ihões foram originários de um empréstimo do Banco Mundial. 0 seu objetivo era expandir, em 18\% dos municípios nordestinos, o acesso das crianças à escola primária, reduzir o desperdício de recursos adicionais com a diminuição das taxas de repetência e evasão e melhorar o rendimento escolar dos alunos com a oferta de instrução de melhor qualidade" (Gomes Neto et al., 1994, p. 47). 
Quadro 1 - Ano de defesa e nivel e totais na área e geral e percentagens

\begin{tabular}{|c|c|c|c|c|c|}
\hline Ano da defesa & Mestrado & Doutorado & Total Area & Total Geral & $\begin{array}{c}\text { Educą̧ão Rural I } \\
\text { Outros tamas \% }\end{array}$ \\
\hline 1981 & 03 & & 03 & 154 & 2 \\
\hline 1982 & 06 & & 06 & 165 & 3,6 \\
\hline 1983 & 05 & & 05 & 238 & 2,1 \\
\hline 1984 & 08 & & 08 & 335 & 2,3 \\
\hline 1985 & 09 & & 09 & 227 & 4,0 \\
\hline 1986 & 01 & & 01 & 227 & 0,4 \\
\hline 1987 & 04 & 01 & 05 & 270 & 1,9 \\
\hline 1988 & 03 & 01 & 04 & 375 & 1,1 \\
\hline 1989 & 07 & & 07 & 451 & 1,5 \\
\hline 1990 & 07 & & 07 & 460 & 1,5 \\
\hline 1991 & 04 & & 04 & 461 & 0,9 \\
\hline 1992 & 09 & & 09 & 624 & 1,5 \\
\hline 1993 & 03 & 01 & 04 & 614 & 0,6 \\
\hline 1994 & 05 & 01 & 06 & 698 & 0,9 \\
\hline 1995 & 06 & & 06 & 802 & 0,75 \\
\hline 1996 & 04 & & 04 & 835 & 0,5 \\
\hline 1997 & 05 & 03 & 08 & 891 & 0,9 \\
\hline 1998 & 03 & 03 & 06 & 860 & 0,7 \\
\hline T01AL & 92 & 10 & 102 & 826 & 1,2 \\
\hline
\end{tabular}

Área de Educação Rural - 1981/1998 - Dissertações e Teses - Banco de Dados da ANPEd 1999

parêntese para uma breve reflexão sobre a relativa coerência entre os interesses dominantes no Estado e os interesses dominantes na Universidade. Em função do financiamento prioritário do Estado de determinadas áreas de pesquisa, as universidades e demais centros de pesquisa acabam também concentrando a sua atenção nas mesmas áreas e deixando de lado áreas que, embora importantes para a sociedade, são marginais aos interesses do Estado que, por sua vez, decide a prioridade dos seus interesses também pressionado pelas instituições internacionais de crédito, como o Banco Mundial, por exemplo (Gentili, 1998).

0 desinteresse pela educação rural e conseqüentemente pela pesquisa nessa área do conhecimento também reflete, obviamente, o limite da pressão dos movimentos sociais rurais sobre o poder público. Inclusive, o recente interesse por esta área, verificado nos últimos dez anos, mas insignificantemente expresso nas percentagens abaixo, está relacionado ao poder de pressão do Movimento dos Trabalhadores Sem-Terra. Apesar desse fato, o interesse pela pesquisa na área continua insignificante em re- lação à pesquisa nas demais áreas. Isto é, observamos, estudando o Quadro 1, que a percentagem média de produção de dissertações e teses cai de $2,1 \%$, na década de 1980 , para 0,9\% na década de 1990, o que revela o crescente desinteresse por esta área de estudos. Fenômeno semelhante é observado na produção acadêmica veiculada em revistas científicas, conforme apresentado nos quadros 5 e 6 (Anexo). Observa-se uma média de apenas dois artigos sobre educação rural publicados por ano. A publicação de livros, conforme pode ser conferido na bibliografia, também acompanha esta mesma tendência confirmando que a educação rural é considerada tema de menor importância tanto pelo governo federal quanto pelas universidades e centros de pesquisa.

De um certo modo, a marginalização da educação rural revela-se também nas temáticas privilegiadas pelos estudos realizados, como observaremos a seguir, na discussão sobre os temas. Após separarmos as 102 dissertações e teses encontradas no banco de dados 1981 1998 da ANPEd, nós as classificamos sob os seguintes temas: 
Quadro 2 - Temas

\begin{tabular}{|l|c|c|}
\hline \multicolumn{1}{|c|}{ Tema } & Quantidade & $\%$ \\
\hline Ensino fundamental (escola rural) & 15 & 14,7 \\
\hline Professores rurais & 09 & 8,8 \\
\hline Políticas para a educação rural & 18 & 17,6 \\
\hline Currículos e saberes & 14 & 13,7 \\
\hline Educação popular e movimentos . sociais no campo & 22 & 21,5 \\
\hline Educação e trabalho rural & 08 & 7,8 \\
\hline Extensão rural & 07 & 6,8 \\
\hline Relações de gênero TOTAL & 03 & 2,9 \\
\hline Outros & 06 & 5,8 \\
\hline \multicolumn{1}{|c|}{$\quad \mathbf{1 0 2}$} & $\mathbf{1 0 0}$ \\
\hline
\end{tabular}

Área de Educação Rural - 1981/1998 - Dissertações e Teses Banco de Dados da ANPEd 1999

Sob o tema Ensino fundamental (Escola rural) incluimos todos os trabalhos que analisam, discutem ou avaliam as condições gerais do ensino e da aprendizagem na escola rural.

Tais estudos apresentam dados que permitem concluir que a educação rural apresenta problemas graves de origem; ou seja, planejada a partir da escola urbana, a escola rural parece tão alienada do seu meio quanto o são também as escolas urbanas para as classes populares (Willis, 1991). Deste modo, as pesquisas recorrentemente confirmam as discrepâncias existentes entre as expectativas do planejamento governamental e as das populações rurais beneficiárias. Afirmam, portanto, que, tal como se apresenta, a escola rural é inadequada ao seu meio (Leite, 1999; Moreira; Silva, 1994; McLaren, 1997; Damasceno; Therrien, 2000). Apesar de reconhecerem que a escola pública rural é limitada e precária, tanto as populações rurais pesquisadas como os estudiosos consideram que essa instituição tem papel fundamental na divulgação do saber universal para a população rural, devendo por isso ser avaliada e, sobretudo, ter sua função sociopedagógica e conteúdos curriculares redefinidos para que de fato venha a atender aos reais interesses dos grupos sociais a que se destina (Damasceno, 1995, 1998, Grecio, 1982; Almeida, 1990; Martins, 1982, 1992; Maurício, 1989; Rizzoli, 1988; Viana, 1982).

Os estudos envolvendo este tema e os dois seguintes, Professores rurais e Políticas para a educação rural, buscam dar suporte científico tanto à formulação de políticas quan- to de programas educacionais adequados à realidade da população camponesa. Assim, as pesquisas nessa área procuram contemplar a ação do Estado, como instância formuladora de políticas educativas, analisar as condições da rede escolar existente e, ainda, compreender a ação pedagógica realizada nesse contexto, enfatizando a formação do professor, sua prática pedagógica e suas condições de vida e de trabalho (Barreto, 1983; Spayer, 1983; Therrien, 1987, 1988; Freitas, 1990; Reis, 1992).

Embora o problema do descompasso entre a realidade da vida rural e a escola rural seja tratado sob o tema Políticas para a educação rural, é sob o tema Currículos e saberes que relacionamos os trabalhos que discutem diretamente a questão. Vê-se, portanto, nesses trabalhos que é grande a distância entre o currículo da escola rural e a vida da sua clientela, conseqüência evidente do desconhecimento das populações-alvo pela burocracia que planeja (Brandão, 1997; Caldart, 2001; Furtado, 1997; Queiroz, 1992; Rivas, 1992).

Apesar de enfatizar aspectos distintos, os primeiros quatro temas relacionados se referem ao estudo da escola rural como ela é. Considerado individualmente, é o tema Educação popular e movimentos sociais no campo que mais concentra a atenção dos estudiosos. Na verdade, interesse tão especial busca encontrar, nesses espaços alternativos de educação, pistas para a solução dos problemas existentes na escola rural. Além disso, esses estudos compreendem que a educação não se limita apenas ao espaço escolar, mas está também presente nas diversas expressões da luta social e é justamente a participação nesta luta que cria as condições de produção e apropriação de um saber que permite uma compreensão transformadora da realidade.

As práticas educativas dos movimentos sociais compreendem, portanto, um vasto e rico campo que vem sendo investigado, destacando-se o próprio processo de constituição desses movimentos, o estudo do conjunto das ações que seus atores desenvolvem para a construção de sua identidade como sujeitos 
coletivos e, também, o saber gestado no cotidiano dessas lutas.

Em suma, essa vertente de pesquisa parte da premissa de que no tocante à educação rural é preciso considerar, no conjunto dos saberes historicamente produzidos, aquele saberes gerados pelos atores sociais em suas práticas produtivas e políticas, tendo em vista que esses saberes têm especificidades em virtude das diversificadas condições de vida e trabalho. Por conseguinte, diferentes formas de organização criam variadas visões de mundo nas quais novos processos educativos são permanentemente elaborados (Brandão, 1997; Caldart, 2000, 1997, 1996, 1995; Calado, 1993; Damasceno, 1998, 1994, 1992, 1990; Furtado, 2000, 1998; Grzybowski, 1986, 1982; Souza, 1989; Therrien, 1991; Vendramini, 1997).

As investigações têm constatado ser de fundamental importância averiguar os condicionantes estruturais e conjunturais que produzem e reproduzem as ações educativas, bem como os atores sociais das referidas práticas com suas lutas, representações e identidades.

Tais estudos também mostram que os movimentos sociais no campo, especialmente o Movimento dos Trabalhadores Sem-Terra, vêm se constituindo em espaços privilegiados de resistência, de luta e, conseqüentemente, de organização de um saber que traduz a realidade de seus atores. Assim, o ato de repensar a educação deve ser mediado pelos interesses do grupo a quem ela se destina, especialmente por aqueles interesses expressos através dos movimentos sociais, posto ser esta a instância de compreensão e reelaboração do saber nas relações sociais dos atores envolvidos (Caldart, 1999).

Também relacionados com os saberes que se produzem nas práticas sociais estão os três últimos temas: Educação e trabalho rural, Extensão rural e Relações de gênero. No caso do primeiro, a atenção se concentra na relação entre educação escolar e educação do trabalho, mostrando ora como a educação rural está distante da realidade do trabalho rural ou como uma influencia a outra, seja positiva ou negativamente (Bianchetti, 1982; Souza, 1990; Almeida, 1990; Masseli, 1998). Seguindo a triIha proposta por Paulo Freire (1975a), os estudos sobre a Extensão rural também discutem o problema da comunicação entre duas lógicas que se negam. A Extensão rural, concebida como alternativa instrumental à educação universal no campo, também se constitui num espaço de domínio do rural pelo urbano e apresenta basicamente as mesmas dificuldades da escola pública rural. Tanto uma como a outra convivem com o problema de incutir no homem do campo um saber que não necessariamente lhe interessa ou do qual ele possa tirar proveito nas suas práticas sociais. 1sto, claro, é completamente diferente de propostas alternativas elaboradas pelos próprios grupos sociais interessados e a partir dos seus interesses (Arroyo, 1982; Beserra, 1994, 1996; Caldart, 1995; Camini, 1998; Damasceno, 1992, 1994; Damasceno; Therrien, 1993; Furtado, 2002, 2000, 1998; Holanda, 2000; lbanez, 1995; Janes, 1998; Masselli, 1994; Melo, 1983; Pontes, 1990; Portilho, 1998; Queda, 1982).

Finalmente, sob Relações de gênero estão estudos específicos sobre a mulher professora ou camponesa e a educação rural. São estudos mais recentes que revelam a influência dos novos movimentos sociais que incluem, dentre outras novidades, a atenção a grupos sociais que, embora também façam parte da classe trabalhadora, têm características específicas que precisam ser consideradas separadamente (Nodari, 1987; Vigolvino, 1989; Werle, 1992).

A leitura do resumo desses trabalhos revela também que são estudos pontuais, raramente parte de projetos mais abrangentes, o que nos leva a supor que o seu impacto é também bastante limitado. São estudos de cunho socioantropológico desenvolvidos em geral por indivíduos ligados - por razões pessoais ou de ofício - às populações rurais. Em seu conjunto, porém, representam grande contribuição à compreensão da educação rural no Brasil. 


\section{Estudos sobre a educação rural no Brasil: distribuição por região e instituições de ensino}

Os quadros 3 e 4 , a seguir, mostram a distribuição de estudos na área de educação rural por instituição de ensino superior e por região. Vê-se, como esperado, a concentração de estudos (55\%) na região Sudeste, o que é uma conseqüência da concentração do processo de desenvolvimento do país naquela região. Em seguida, vêm o Sul e Nordeste com, respectivamente, 24 e 15\% da produção nacional na área. Os motivos pelos quais essas regiões aparecem nesta ordem são praticamente os mesmos que explicam o primeiro lugar da região Sudeste. Ou seja, pela proximidade do Sudeste, o Sul é o beneficiário mais imediato da expansão do desenvolvimento nacional que inclui, entre outras coisas, a criação de instituições de ensino superior e a qualificação dos seus profissionais. lsso porque, na verdade, o que esta concentração de estudos e pesquisas revela é que foi nessas regiões que os primeiros programas de pós-graduação foram implantados.

Considerando o número de instituições de ensino superior nas diversas regiões e o periodo de criação dos seus programas de pósgraduação, podemos afirmar que a proporção de estudos na área de Educação Rural é maior no Sul e Nordeste. Tal fenômeno pode estar relacionado com fatores como a importância do rural nessas regiões, em primeiro lugar, e, em decorrência disso, a formação de grupos de pesquisa dedicados ao tema. 0 caso da pesquisa desenvolvida por professores da Universidade Federal do Ceará sobre o Edurural é um exemplo disso. Tal investigação foi o ponto de partida para a composição de um grupo de estudo que se consolidou e, com o apoio do $\mathrm{CNPq}$, desenvolveu vários projetos de pesquisa voltados para a problemática da educação rural, fato que possibilitou a produção e a publicação de diversos artigos e livros, além da orientação de dissertações e teses nas décadas examinadas. Uma das conseqüências desse esforço é que o referido grupo exerceu a liderança nacional nessa área temática, inclusive coordenando os GTs de Educação Rural e Educação e Movimentos Sociais no Campo da ANPEd por mais de uma década.

Quadro 3 - Produçăo cientifica por Instituiçăo de Ensino Superior

\begin{tabular}{|l|c|c|c|}
\hline \multicolumn{1}{|c|}{ Instituição } & Mestrado & Doutorado & TOTAL \\
\hline PUC-SP & 09 & & 09 \\
\hline PUC-RS & 08 & & 08 \\
\hline UFRGS & 06 & 02 & 08 \\
\hline UNICAMP & 05 & 02 & 07 \\
\hline UFRJ & 07 & & 07 \\
\hline UFC & 07 & & 07 \\
\hline PUC-RJ & 07 & & 07 \\
\hline UFMG & 06 & & 06 \\
\hline USP & & 05 & 05 \\
\hline UNB & 05 & & 05 \\
\hline UFPR & 05 & & 05 \\
\hline UF SANTA MARIA & 04 & & 04 \\
\hline UFRM & 04 & & 04 \\
\hline UFES & 03 & & 03 \\
\hline UF SĀO CARLOS & 02 & 01 & 03 \\
\hline UFPB & 02 & & 02 \\
\hline UFBA & 02 & & 02 \\
\hline UFF & 02 & & 02 \\
\hline UF UBERLÃNDIA & 02 & & 02 \\
\hline UNESP & 01 & & 01 \\
\hline UERJ & 01 & & 01 \\
\hline UMNCATÓUCADEPEIRÓPOLIS & 01 & & 01 \\
\hline UFMS & 01 & & 01 \\
\hline UFSC & 01 & & 01 \\
\hline IESA/FCV & 01 & & 01 \\
\hline
\end{tabular}

Área de Educação Rural - 1981/1998 - Dissertaçőes e Teses Banco de dados da ANPED, 1999

Quadro 4 - Produção Científica por região

\begin{tabular}{|c|c|c|c|}
\hline Região & Mestrado & Doutorado & TOTAL \\
\hline Sudeste & 47 & 08 & $\mathbf{5 5}$ \\
\hline Sul & 24 & 02 & $\mathbf{2 6}$ \\
\hline Nordeste & 15 & & $\mathbf{1 5}$ \\
\hline Centro Oeste & 06 & & $\mathbf{0 6}$ \\
\hline Total & & & $\mathbf{1 0 2}$ \\
\hline
\end{tabular}

Área de Educação Rural (1981-1998)

Banco de dados da ANPED, 1999.

\section{Conclusões: tendências dos estudos de educação rural}

Considerados em relação aos estudos sobre educação rural desenvolvidos nas décadas anteriores, os estudos aqui enfocados (1981-1998) caracterizam-se por uma preocupação cada vez maior em discutir o problema da educação rural da perspectiva da população a que se destina, ou seja, os trabalhadores rurais. Tal tendência, porém, não nasce da 
clarividência ou excessiva sensibilidade dos estudiosos do tema, mas das próprias circunstâncias da realidade sob estudo, ou seja, são os próprios trabalhadores rurais que, por meio de sua organização política, tornam-se suficientemente visiveis para chamarem sobre si a atenção dos estudiosos. A partir daí a educação rural deixa de fazer parte apenas de um plano geral de desenvolvimento da nação e torna-se uma reivindicação de uma classe social. Em gestação desde os movimentos camponeses das décadas de 1950-60, esta tendência se consolida com o surgimento do Movimento dos Sem-Terra (MST). Nesse sentido, é interessante observar que mesmo sem serem guiados pelos mesmos interesses teórico-metodológicos, a maioria dos estudos produzidos na área apresenta dados que instigam a discussão de propostas alternativas de educação rural em cujo centro estejam os interesses dos trabalhadores rurais. A disposição de experimentar novas práticas educativas, porém, parece nascer mais do conhecimento de práticas já testadas noutros países, como é o caso das Escolas Família Agrícola (EFA) e das Casas Familiares Rurais (CFR), do que propriamente da sugestão de resultados de pesquisas acadêmicas (Furtado, 2003). Um estudo recente traz uma abordagem detalhada dessas novas experiências no campo da educação rural no Brasil, inclusive da Escola Ativa (Bof; Morais; Silva, 2003).

É talvez porque tal compreensão abrange tanto os movimentos sociais quanto a produção acadêmico-universitária que os novos programas de Educação Rural, de iniciativa do Estado ou dos próprios trabalhadores rurais, refletem uma experiência rica em exemplos sobre o que faz ou não sentido em educação rural e refletem principalmente a diferença de uma experiência de cuja execução os próprios interessados participam.

Detenhamo-nos por alguns instantes nas tendências práticas da educação rural para depois voltarmos a relacioná-las aos estudos produzidos.
Uma das novidades dos últimos anos é de iniciativa do Estado (nos âmbitos federal, estadual e municipal) e visa atender à Constituição de 1988, que determina a obrigatoriedade do ensino fundamental para todas as crianças. Compete, portanto, à União, estados e municípios proporcionar meios de acesso à educação, garantindo, inclusive, o transporte dos alunos do ensino fundamental. Isso significa que o poder público precisa garantir a igualdade de condições para o acesso e permanência dos alunos na escola independente do local onde residam.

Desse modo, a escolinha isolada e as suas classes multisseriadas, que já foram o retrato mais comum do ensino no meio rural brasileiro, vêm se tornando cada vez mais raras em muitas regiões do país. Observa-se, em contrapartida, a aglutinação de escolas e, conseqüentemente, a concentração de alunos de uma dada área numa mesma escola de maior porte, seguindo o modelo do grupo escolar urbano, tornando-se, assim, possível levar para o campo o ensino fundamental completo, com a inclusão do ensino de quinta à oitava série. Tal transformação requer grandes investimentos em dois setores: a) o da construção de escolas maiores, com várias salas de aula, para comportar os estudantes da microrregião onde a escola se situa e b) o do transporte escolar, serviço que os municipios implantaram para cumprir a lei que os obriga a manter as crianças na escola. É óbvio que tal projeto é tanto mais viável quanto maior a concentração demográfica das diversas áreas rurais e, em implantação, não foi ainda submetido a uma avaliação mais sistemática e profunda.

A segunda tendência nasce no seio dos movimentos sociais e procura atender o princípio da adequação do ensino aos interesses das populações rurais. Conforme evidenciam os estudos que discutem o significado da escola rural para o camponês (Damasceno, 1995, 1998; Brandão, 1997; Furtado, 1998; Caldart, 1995), o movimento social do campo vem realizando ações com vistas à construção de uma escola pública sintonizada com os interes- 
ses dos seus beneficiários, os camponeses. $\mathrm{Na}$ concretização dessa escola torna-se necessário deslocar radicalmente os sujeitos e os propósitos da educação escolar, colocando no centro os usuários e seus interesses. Isso significa, em última instância, que a luta pela escola do trabalhador rural está intimamente vinculada à luta pela superação das desigualdades sociais. As pesquisas mostram também que, embora a realização do projeto político-pedagógico da escola do trabalhador rural seja uma tarefa complexa, o próprio movimento popular vem historicamente atuando na sua construção, tendo em vista que esta nova escola torna-se cada vez mais necessária como instrumento de apoio técnico, intelectual e político nas lutas que os camponeses travam diariamente. 0 caminho apontado para se redimensionar a educação rural consiste em privilegiar o próprio produtor rural (como entidade coletiva na sua atividade real e nas suas lutas) como sujeito desse processo de recriação da educação e da escola, visando a recriação da cultura mediante a apropriação do saber e a reelaboração deste em função dos seus interesses.

No cerne desse processo de reelaboração do saber encontra-se a necessidade de uma efetiva articulação entre a prática pedagógica realizada pela escola (que deve ser redimensionada) e as práticas sociais dos camponeses. Isso implica em transformar a escola num instrumento que opere a vinculação do saber sistematizado, dito universal, com o saber alternativo que vem sendo gestado nas práticas das lutas sociais. Assim, como propõe Arroyo (1987), se quisermos que a escola pública não murche ainda mais precisamos enxertá-la na árvore vigorosa e florescente dos movimentos sociais, pois esse caminho permite que o trabalhador passe da condição de receptor para a de produtor do conhecimento. Na condição de sujeitos que pensam a sua história, esses trabalhadores têm consciência de que escola querem e dos conteúdos intelectuais e morais que ela deve produzir e transmitir: a escola deveria preparar o aluno para não aceitar essa situação onde poucos têm muito e a maioria não tem nem o que comer (...) sei que é difícil mas a escola devia se preocupar com o trabalho da gente, que dá duro todo dia; penso que as professoras e os trabalhadores juntos podiam fazer uma escola diferente. (Damasceno, 1998, p. 140)

Em suma, na visão de parte dos trabalhadores rurais, notadamente daqueles que integram o Movimento dos Sem-Terra, o eixo para se buscar a transformação da educação reside em considerar as relações de trabalho (incluindo sua dimensão sociopolítica, representada pelas lutas sociais) como as bases a partir das quais a educação popular como um todo e a escola em particular devem ser repensados. Coerentes com tais diretrizes, as experiências direcionadas para a construção da escola do trabalhador do campo vêm privilegiando a gestão democrática da escola pública nos níveis político, administrativo e pedagógico.

As transformações ainda em curso na escola pública rural, em conseqüência das novas exigências constitucionais, estão ainda por ser avaliadas pelo próprio fato de não terem ainda a abrangência geográfica ou o tempo de experiência indispensável para isto. Estudos sobre outros aspectos da escola rural continuam sendo desenvolvidos porque os problemas que os motivam persistem. Desse modo, dentro da relativa escassez que caracteriza os estudos no campo da Educação Rural, há uma certa abundância de estudos que mostra a precariedade das condições físicas e intelectuais da escola rural. E, como já mencionamos anteriormente, em função do espaço que o movimento social no campo passou a ter na definição de políticas educacionais rurais, há uma grande quantidade de estudos sobre a incompatibilidade entre o atual projeto de educação rural definido do ponto de vista das necessidades e valores da cidade e um novo e futuro projeto que considere as necessidades e valores das populações rurais. 
Os estudos que se concentram em relacionar e discutir a discrepância entre a educação rural oferecida hoje pelo Estado e a desejada pelo movimento dos trabalhadores rurais caracterizam-se, em geral, pela adoção de uma perspectiva teórico-metodológica claramente política, o que é interessante na medida em que questiona de frente a suposta neutralidade científica, mas, por outro lado, leva à produção de vários problemas. Por exemplo, há, de um lado, um senso crítico agudíssimo que funciona para a análise dos projetos e experiências governamentais e, de outro lado, uma certa condescendência em relação aos projetos e experiências populares. Apesar dessas limitações, esses estudos são importantes porque trazem à tona aspectos da realidade nem sempre conhecidos pelos planejadores, embora saibamos que o conhecimento da realidade não oferece em si nenhuma garantia da sua transformação. Ou seja, não é por desconhecimento da realidade que as políticas sociais são precárias, mas porque os recursos públicos dirigidos ao trabalho e à sua reprodução são evidentemente limitados numa sociedade que se caracteriza pela exploração do trabalho pelo capital. Isso não significa que as massas trabalhadoras não possam, aqui e ali, e em função do seu poder de pressão, ampliar os seus direitos, mas não podemos esquecer que nesses tempos de políticas neoliberais as conquistas populares têm ficado cada vez mais restritas.

Esses estudos, portanto, denunciam fatos e apontam caminhos, mas não preenchem as tantas lacunas existentes no projeto de um conhecimento mais abrangente e mais profundo da educação rural ou educação no campo, como alguns pesquisadores e políticos preferem nomeá-la em função da abrangência exagerada e conteúdo político do termo rural. Nesse sentido, não seria extravagante propor um programa de ação afirmativa para essa área de estudos. A exemplo de outras áreas, como a da Educação Afrodescendente, seria de fundamental importância para o fortalecimento da área que as instituições financiadoras de pesquisa abrissem concursos ou programas específicos de pesquisa sobre a educação rural e que o Ministério da Educação oferecesse incentivo especial aos estudantes e pesquisadores que escolhessem enfrentar tal temática.

Uma vez criadas as condições de pesquisa, há uma diversidade de temas cujo desenvolvimento levaria o conhecimento sobre a educação rural para um outro patamar. Um primeiro aspecto a se considerar atualmente é o de que, ao contrário de outros períodos históricos, este é particularmente favorável à tarefa de se repensar o rural/campo porque a crise da urbanização e a incipiente consciência da necessidade de um desenvolvimento sustentável criaram um espaço especial para isto. Por outro lado, a própria organização camponesa criou efetivamente as condições para se repensar o campo sobre bases não necessariamente urbanas. Considerados esses aspectos, e os já discutidos ao longo do artigo, sugerimos que, além dos temas mais comumente explorados, que são os relacionados no Quadro 1, seria de enorme utilidade a produção de estudos sobre a história da educação rural nas diversas regiões brasileiras. ${ }^{11}$ Estudos mais abrangentes, que incluam dados quantitativos e qualitativos, também fariam grande diferença para um conhecimento mais profundo sobre a área. Finalmente, considerando a extrema variedade do campo brasileiro, é fundamental a produção de estudos etnográficos que ofereçam elementos para uma ação mais eficaz tanto do Estado quanto dos movimentos sociais. A organização de grupos de pesquisa interregionais que possam desenvolver estudos comparativos também ajudaria bastante a mudar favoravelmente o panorama do conhecimento sobre a educação rural no Brasil e, conseqüentemente, esperamos, influenciar a realização de novas e mais adequadas políticas educacionais para o campo.

11. Embora não tenham aparecido na nossa amostra em número suficiente para figurarem entre as temáticas dominantes, nos últimos cinco anos, os estudos sobre juventude rural têm cada vez mais ocupado a atenção dos estudiosos. Infelizmente a nossa análise interrompe-se no ano de 1998. Ver, entre outros, Andrade (1998). 


\section{Anexo}

\section{Pesquisa Área de Educação Rural - Revistas}

Quadro 5 - Revistas que veicularam artigos sobre educação rural

\begin{tabular}{|l|c|}
\hline \multicolumn{1}{|c|}{ REVISTA } & NÚMERO \\
\hline Revista de Educação Pública (UFMT) & 10 \\
\hline Em Aberto (INEP) & 08 \\
\hline Contexto e Educação (Unijui) & 06 \\
\hline Cadernos Cedes (CEDES) & 06 \\
\hline Educação em Debate (UFC) & 05 \\
\hline Cadernos de Pesquisa (FCCh) & 05 \\
\hline Revista Brasileira de Estudos Pedagógicos (INEP) & 04 \\
\hline Educação em Revista (UFMG) & 03 \\
\hline Revista da Faculdade de Educação (USP) & 03 \\
\hline Revista Brasileira de Educação (ANPED) & 01 \\
\hline Educação e Sociedade (CEDES) & 01 \\
\hline \multicolumn{1}{|c|}{ TOTAL } & $\mathbf{2 6}$ \\
\hline
\end{tabular}

Quadro 6 - Número de artigos por Ano

\begin{tabular}{|c|c|}
\hline Ano & Número \\
\hline 1990 & 01 \\
\hline 1991 & 05 \\
\hline 1992 & 06 \\
\hline 1993 & 07 \\
\hline 1994 & 06 \\
\hline 1995 & 06 \\
\hline 1996 & 01 \\
\hline 1997 & 02 \\
\hline 1998 & 08 \\
\hline 1999 & 05 \\
\hline 2000 & 04 \\
\hline 2001 & 01 \\
\hline 2002 & 01 \\
\hline TOTAL & $\mathbf{5 3}$ \\
\hline
\end{tabular}

\section{Referências bibliográficas}

ALMEIDA, W.A. A dicotomia escola-trabalho no contexto de vida do aluno-trabalhador rural precoce. 1990. Tese (Mestrado)Faculdade de Educação. Universidade Federal do Espírito Santo, Espírito Santo, 1990.

ANDRADE, M.A. A formação da consciência política dos jovens no contexto dos assentamentos do Movimento dos Trabalhadores Rurais sem Terra. 1998. Tese (Doutorado)- Faculdade de Educação UNICAMP, Campinas, 1998.

ARROYO, M. Escola, cidadania e participação no campo. Em Aberto, Brasília, 1982.

. A escola e o movimento social: relativizando a escola. ANDE, São Paulo, n.12, 1987.

BARRETO, E. S. Novas políticas educacionais para a velhas escolas rurais: um estudo de caso. Cadernos de Pesquisa, São Paulo, n. 46, p. 23-49, ago. 1983.

BESERRA, B. Técnicos e camponeses em assentamentos da reforma agrária ou a construção fictícia da aceitação do outro. Boletim do Museu Paraense Emílio Goeldi, Belém, v.12, n.1, 1996.

. A educação popular entre a ciência e a fé. Educação em Debate, Fortaleza, v.16, n. 27, 1994.

BIANCHETTI, L. Educação e trabalho no meio rural: o caso específico da orientação vocacional em escolas rurais do Rio Grande do Sul. 1982. Dissertação (Mestrado)- Faculdade de Educação. Pontifícia Universidade Católica-RJ, Rio de Janeiro, 1982.

BOF, A.; MORAIS, T. C.; SILVA, L. H. A educação no meio rural do Brasil: revisão da literatura. Brasília: INEP/SEIF-MEC. 2003.

BRANDÃO, M. de L. P.Os saberes agrário-agrícolas no projeto formativo da Escola Rural: o currículo como uma política cultural. 1997. Tese (Doutorado)- Faculdade de Educação, Universidade Federal do Ceará, Fortaleza, 1997.

Pró-docente rural: 10 anos de extensão. Educação e Debate, ano 13, n. 19-20, Fortaleza, 1990.

CALADO, A. J. F. Educação popular nos movimentos sociais no campo: potencializando a relação macro/micro no cotidiano como espaço de exercício da cidadania. Educação Popular e Outros Caminhos, João Pessoa, 1993.

CALAZANS, M. J. Educação no meio rural. Educação e Escola no Campo, Campinas, 1993. 
. Estudo retrospectivo da educação rural no Brasil. Rio de Janeiro: IESAE, 1979.

CALDART, R. S. 0 currículo das escolas do MST. Revista Movimento, Niterói, v.3, 2001.

. A escola do campo em movimento. Contexto e Educação, ljui, v.15, 2000.

; Pedagogia do Movimento Sem Terra: escola é mais do que escola. Petrópolis: Vozes, 2000.

. Projeto popular e escolas do campo. Brasília: Articulação Nacional por uma Educação Básica do Campo, 1999.

Educação em movimento: a formação de educadoras e educadores no MST. Petrópolis: Vozes, 1997.

. Os movimentos sociais e a construção da escola (do sonho) possível. Contexto e Educação, ljuí, v. 41, 1996.

. Educação popular no meio rural: as experiências pedagógicas nas escolas do MST. In: SILVA, L.H. da; AZEVEDO, J.C. de

(Org.) Reestruturação curricular. Petrópolis: Vozes, 1995.

CAMINI, I. O cotidiano pedagógico de professores e professoras em uma escola de assentamento do MST: limites e desafios. 1998. Dissertação (Mestrado em Educação)- Faculdade de Educação, Universidade Federal do Rio Grande do Sul, Rio Grande do Sul, 1998.

DAMASCENO, M.N. Pedagogia do engajamento: trabalho, prática educativa e consciência do campesinato. Fortaleza: Ed. UFC/ Stylus Comunicações, 1990.

. A construção do saber social pelo camponês na sua prática produtiva e política. Sociedade Civil e Educação, Campinas, 1992. (Coletânea C.B.E.)

. Pedagogia do enfrentamento no cotidiano das lutas no campo. Cadernos da ANPED, Rio de Janeiro, n.6, 1994.

. 0 saber social e a construção da identidade. Contexto e Educação, ljuí, n. 38, 1995.

. Luta social e escola no campo. Cadernos da Pós-Graduação em Educação, Fortaleza, v.1, n.1, 1995.

. A escola em assentamentos: um retrato em branco e preto. Revista de Educação Pública, Cuiabá, v. 7, n.11, 1998.

DAMASCENO, M. N.; THERRIEN, J. Educação e escola no campo. Campinas: Papirus, 1993.

. Artesões de um outro ofício: múltiplos saberes e práticas no cotidiano escolar. São Paulo: Annablume, 2000.

DEM0< P. Educação rural: sua sintonia com o desenvolvimento. Revista Brasileira de Estudos Pedagógicos, Brasília, v. 63, n. 146, p. $289-298,1980$.

FREITAS, I.D. de. A práxis social do professor rural. 1990. Dissertação (Mestrado)- Faculdade de Educação, Universidade Federal do Ceará, Ceará, 1990.

FREIRE, P. Extensão ou comunicação? Rio de Janeiro: Paz e Terra, 1975a.

FURTADO, E. D. P. 0 estado da arte da educação rural no Brasil. Fortaleza: FAO/UNESCO, 2003. (Relatório de Pesquisa)

Programa Nacional de Educação na Reforma Agrária (PRONERA) no contexto das políticas públicas voltadas à sustentabilidade dos assentamentos rurais. Revista de Educação, Maceió, 2002.

. 0 que se sabe e o que se faz sobre educação no contexto dos assentamentos rurais: colocando gás na lamparina. Educação em Debate, Fortaleza, n. 38, 2000.

. A intervenção participativa dos atores: uma metodologia construída no contexto dos assentamentos rurais do Ceará. Educação em Debate, n.36, 1998. 
. Focusing on curriculum knowledges in the interaction between knowledges in the school quotidian in Brazil. The Curriculum Journal, New Fetter Lane, v.9, n. 3, 1997.

FURTADO, E. D. P.; SOUSA, J. R. F. A intervenção participativa dos atores (INPA): uma metodologia de capacitação para 0 desenvolvimento sustentável. Brasília: IICA, 2000.

GENTILI, P. A falsificação do consenso: simulacro e imposição na reforma educaiconal do neoliberalismo. Petrópolis: Vozes, 1998.

GOMES NETO, J. B. et al. Educação rural. São Paulo: EDUSP, 1994.

GRAZIANO DA SILVA, J. 0 novo rural brasileiro. Revista Nova Economia, v. 1, n. 7, 1999.

GRZYBOWSKI, C. Esboço de uma alternativa para pensar a educação no meio rural. Contexto e Educação, Porto Alegre, n.4, p. 4958, 1986.

GUSSO, D. Educação e desenvolvimento rural no Brasil. Documenta. Brasília, v. 216, p. 64-83, 1978.

GRECIO, D. M. N. Evasão e qualidade de ensino na zona rural: o caso de Cachoeiro de Itapemirim - ES. 1982. Dissertação (Mestrado)- Faculdade de Educação, Universidade Federal do Espírito Santo, Espírito Santo, 1982.

HOLANDA, M. I. M. A construção da identidade coletiva dos sem-terra: um estudo a partir do cotidiano dos alunos do PRONERA. 2000. Dissertação (Mestrado) - Faculdade de Educação, Universidade Federal do Ceará, Ceará, 2000.

IBANEZ, N. R. Caminhos e descaminhos na construção de um práxis educativa entre pequenos produtores rurais assentados e técnicos. 1995. Dissertação (Mestrado)- Faculdade de Educação, Universidade Federal do Ceará, 1995.

JANES, R. Autogestão e educação popular. o MST (Movimento dos Trabalhadores rurais sem Terra). 1998. Tese (Doutorado)Faculdade de Educação, Universidade de São Paulo, São Paulo, 1998.

LEITE, S. C. Escola rural: urbanização e políticas educacionais. São Paulo: Cortez, 1999.

LIMA, M. B. de Do saber da conquista à conquista do saber. educação e autonomia no campo. 1998. Dissertação (Mestrado)Faculdade de Educação, Universidade Federal do Ceará, 1998.

MAIA, E. M. Educação rural no Brasil: 0 que mudou em 60 anos. Em Aberto. Brasília: INEP, v. 1, n. 9, p. 27-33, 1982.

MARTINS, J. de S. Caminhando no chão da noite: emancipação política e libertação nos Movimentos Sociais do Campo. São Paulo: Hacitec, 1989.

. A valorização da escola e do trabalho no meio rural. Em Aberto, Brasília, v.1, n.9, p. 7-18, 1982.

. Educação e cultura nas lutas do campo: reflexões sobre uma pedagogia do conflito. Sociedade Civil e Educação, Campinas: Papirus, 1992. (Coletânea CBE)

MASSELI, M. C. Extensão rural entre os sem-terra. Piracicaba: Editora UNIMEP, 1998.

A extensão rural em questão: problemas e conquistas a partir da situação de assentamento. 1994. Dissertação (Mestrado)- Faculdade de Educação, UNICAMP, Campinas, 1994.

MAURíCIO, V. R. B. A escola nas escolas. Porto Alegre: representações de professores, pais e alunos de Monte Bonito/Pelotas. 1989. Dissertação (Mestrado)- Faculdade de Educação, Pontifícia Universidade Católica, Porto Alegre, 1989.

MCLAREN, P. A vida nas escolas. Porto Alegre: Artes Médicas, 1997.

MELO, M. S. O trabalho de extensão rural como processo educativo atende às necessidades e aspirações da população rural de Viçosa, MG? 1993. Dissertação (Mestrado)- Faculdade de Educação, Universidade Federal do Rio de Janeiro, Rio de Janeiro, 1983. 
MOREIRA, F.; SILVA, T. Currículo, cultura e sociedade. São Paulo: Cortez, 1994.

NODARI, L. C. L. Núcleos femininos no meio rural do Nordeste do RS: o proposto e o real da ação educativa dos comunicadores. 1987. Dissertação (Mestrado)-Faculdade de Educação, Universidade Federal do Rio Grande do Sul, Porto Alegre, 1987.

PADILHA, R. F.A extensão rural face à problemática da pequena produção no Brasil: extensão e formação profissional rural. Caderno ANPED, Rio de Janeiro, n.1, 1982

PINTO, J. B. A educação de adultos e o desenvolvimento rural. In: WERTLHEIN, J.; BORDENAVE, J. D. Educação rural no terceiro mundo. Rio de Janeiro: Paz e Terra. 1981.

PALMEIRA, M. J. de 0. et al. Educação e a construção da cidadania do homem do campo. Salvador: UFBA/Empresa Gráfica da Bahia, 1990.

PONTES, R.M. A proposta participativa da extensão rural do Paraná de 1980 a 1986. 1990. Dissertação (Mestrado)- Faculdade de Educação, Universidade Federal de São Carlos, São Carlos, 1990.

PORTILHO, M. S. B. Extensão rural: o fio e a trama na construção da representação social do pequeno produtor. 1998. Dissertação (Mestrado)- Faculdade de Educação, Universidade Federal de Uberlândia, Uberlândia, 1998.

PORTO, M. R. S. Imaginário, cultura e escola rural. Em Aberto, Brasília, ano 14, n.61, 1994.

QUEDA, 0. Extensão rural: para que e para quem serve. Cadernos ANPED, Rio de Janeiro, n. 1, p. 17-22, 1982.

QUEIROZ, M. A. Educação e o nordeste: para que um programa de expansão e melhoria da educação nomeio rural? Natal: Edições UFRN, 1990.

QUEIROZ, Z. F. de. A escola rural e a questão do saber. do saber universal ao saber construído pelo homem do campo. 1992. Dissertação (Mestrado)- Faculdade de Educação, Universidade Federal do Ceará, Fortaleza, 1992.

REIS, W. G. dos Do desespero à esperança: a luta sócio-educativa dos professores municipais do interior do Ceará. 1992. Dissertação (Mestrado)- Faculdade de Educação, Universidade Federal do Ceará, Ceará, 1992.

RIBEIRO, D. Sobre o óbvio. Encontros com a civilização brasileira, Rio de Janeiro, n.1, 1978.

RIVAS, N. P. A dinâmica do currículo para a área rural em face das novas relações de trabalho no campo. 1992. Dissertação (Mestrado)-Faculdade de Educação, Universidade Federal do Paraná, Curitiba, 1992.

RIZZOLI, A. O real e o imaginário na educação rural: município de São Carlos. 1988. Tese (Doutorado)- Faculdade de Educação, Universidade de São Paulo, São Paulo, 1988.

SORJ, B. A reforma agrária em tempos de democracia e globalização. Novos Estudos CEBRAP, São Paulo, n. 50, 1998.

SOUZA, J. N. As lideranças comunitárias nos movimentos de educação popular em áreas rurais: uma questão desvendada. 1989. Dissertação (Mestrado) - Faculdade de Educação, Universidade Federal do Rio Grande do Norte, Rio de Grande do Norte, 1989.

SOUZA, M. da C. N. Escola e trabalho no meio rural: uma análise do calendário do caju em Alagoinha, Mossoró, RN. 1990. Dissertação (Mestrado) - Faculdade de Educação, Universidade Federal do Rio Grande do Norte, Natal, 1990.

SPAYER, A. M. Educação e campesinato: uma educação para o homem do meio rural. São Paulo, Loyola, 1983.

THERRIEN, J. A professora leiga e o saber social. Cadernos SENEB, Brasília: MEC, 1991.

. Os movimentos sociais e a compreensão da escola no meio rural: um eixo de análises. Educação em Debate, Fortaleza, jul./dez. 1987.

. Políticas de educação para o meio rural: o papel do estado e a produção do saber. In: CONGRESSO BRASILEIRO DE EDUCACÃO, 4., 1988, São Paulo. Anais... São Paulo: Cortez, 1988. 
VEIGA, J. E. da. Cidades imaginarias: o Brasil é menos urbano do que se calcula. Campinas: Ed. Autores Associados, 2002.

VENDRAMINI, C. R. Consciência de classe e experiências sócio-educativas do Movimento dos Trabalhadores Rurais sem Terra. 1997. Tese (Doutorado)- Faculdade de Educação, Universidade Federal de São Carlos, São Paulo, 1997.

VIANA, V. M. Escola rural de primeiro grau: estudo de uma realidade, 1982. Dissertação (Mestrado)- Faculdade de Educação, Universidade Federal do Rio de Janeiro, Rio de Janeiro, 1982.

VIEIRA, B. O. Experiências de desenvolvimento social de comunidades rurais no Brasil. In: SEMINÁRIO LATINO-AMERICANO DO BEM-ESTAR RURAL, 1954, Rio de Janeiro. Anais..., Rio de Janeiro, 1954.

VIGOLVINO, M. D. Mulher-professora rural: vida e trabalho. 1989. Dissertação (Mestrado)- Faculdade de Educação, Pontifícia Universidade Católica-RJ, Rio de Janeiro, 1989.

WEREBE, M. J. G. Ensaio rural: grandezas e misérias do ensino no Brasil. São Paulo: Difusão Européia do Livro, 1968.

WERLE, E. T. A consciência do processo evolutivo da condição feminina da mulher no meio rural e urbano. 1992. Dissertação (Mestrado)- Faculdade de Educação, Pontifícia Universidade Católica-RS, Porto Alegre, 1992.

WILLIS, P. Aprendendo a ser trabalhador. Porto Alegre: Artes Médicas, 1991.

Recebido em 05.03.04

Aprovado em 28.04.04

Maria Nobre Damasceno é doutora em educação pela Universidade Federal do Rio Grande do Sul, pesquisadora do CNPq e professora colaboradora do Programa de Pós-Graduação em Educação da Universidade Federal do Ceará.

Bernadete Beserra é PhD em Antropologia pela Universidade da Califórnia, é professora-adjunta da Universidade Federal do Ceará. 